\title{
Could Congenital Ocular Motor Apraxia be Caused by a Celebeller Vermis Dysfunction?
}

\author{
Hideki Chuman*, Yuki Inoue, Nobuhisa Nao-I \\ Department of Ophthalmology, Miyazaki Medical College Hospital, Japan
}

Submission: November 20, 2017; Published: December 13, 2017

*Corresponding author: Hideki Chuman, Department of Ophthalmology, Miyazaki Medical College Hospital, 5200 Kihara Kiyotake, Miyazaki, 8891692, Japan, Tel: 81-985-85-2806; Fax: 81-985-84-2065; Email: 06121028@fc.miyazaki-u.ac.jp

\begin{abstract}
Background: Congenital ocular motor apraxia (COMA) is thought to be caused by a dysfunction of the frontal eye field. Joubert syndrome is a syndrome which is characterized by COMA, pigmentary retinopathy, global developmental delay and hypolasia of the cerebeller vermis (molar tooth sign) upon magnetic resonance imaging. We observed seven cases of COMA, Joubert syndrome, and ependymoma which compressed the cerebeller vermis. All cases demonstrated head thrust movement. We will describe these clinical characteristics and discuss the hypothesis that congenital ocular motor apraxia was caused by a dysfunction of celebeller vermis.
\end{abstract}

Methods: Observational case study and review of literature.

Results: We diagnosed case1 to have classic COMA because of the absence of hypolasia of the cerebeller vermis and other neurological abnormalities. We diagnosed cases 2 through 5 to have Joubert syndrome due to the presence of molar tooth sign. We thought that case 6 is between the classic COMA and Joubert syndrome because the clinical presentation is typical for COMA and brain MRI showed very mild cerebeller change but not typical molar tooth sign. We noted head thrust movement in a patient with ependymoma (case 7), which compressed the cerebeller vermis.

Conclusions: Based on the findings of our cases and a review of both the clinical and experimental evidence, we speculated that congenital ocular motor apraxia, as characterized by head thrust, could be caused by a dysfunction of the cerebeller vermis.

Keywords: Joubert syndrome; Congenital ocular motor apraxia; Hypoplasia of the cerebeller vermis

\section{Introduction}

Congenital ocular motor apraxia (COMA) is thought to be caused by a dysfunction located somewhere between the frontal eye field and the paramedian pontine reticular formation (PPRF) [1,2]. However, the exact pathological place and process has yet been known. Joubert syndrome is a syndrome which is characterized by COMA, pigmentary retinopathy, global developmental delay and molar tooth sign upon magnetic resonance imaging [1-6]. We observed seven cases of COMA, Joubert syndrome, and ependymoma which compressed the cerebeller vermis. All cases demonstrated head thrust movement. We herein describe these clinical characteristics and discuss the hypothesis that congenital ocular motor apraxia was caused by a dysfunction of the celebeller vermis.

\section{Case Report}

\section{Case 1}

A six-month-old boy was noted to have an abnormal head movement. His past medical and family history were unremarkable. He demonstrated head thrust movement whenever he tried to look at something (Figure 1). The findings of biomicroscopic and fundus examinations were normal. Brain MRI findings were normal (Figure 2). He did not show any developmental delay or walking disability up until 6 years of age.

\section{Case 2}

A 14-year-old boy had been noted to have an abnormal head movement since 6 months of age. His past medical and family history were unremarkable. He demonstrated head thrust movement whenever he tried to look at something. He showed saccadic pursuit. Fundus examination demonstrated pigmentary retinopathy (Figure 3). Brain MRI showed hypoplasia of the cerebeller vermis (Figure 4). He showed both a developmental delay as well as an impaired walking ability.

\section{Case 5}

A two-year-old girl had been noted to have an abnormal head movement since 6 months of age. Her past medical and 


\section{JOJ Ophthalmology}

family history were unremarkable. She demonstrated head thrust movement whenever she tried to look at something. Biomicroscopic and fundus findings examination were normal.
Brain MRI showed hypoplasia of the cerebeller vermis. She had both a developmental delay as well as an impaired walking ability.

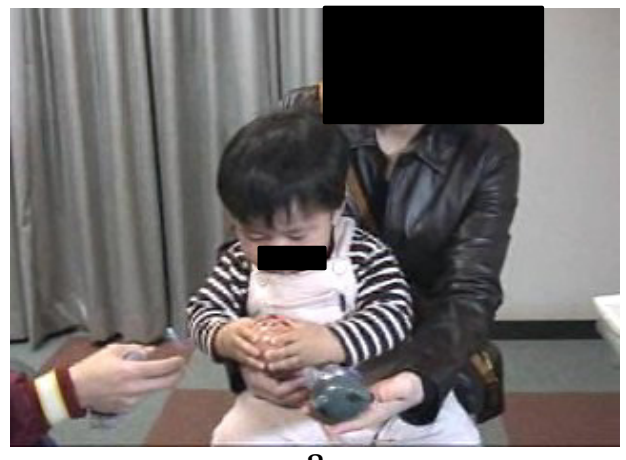

a

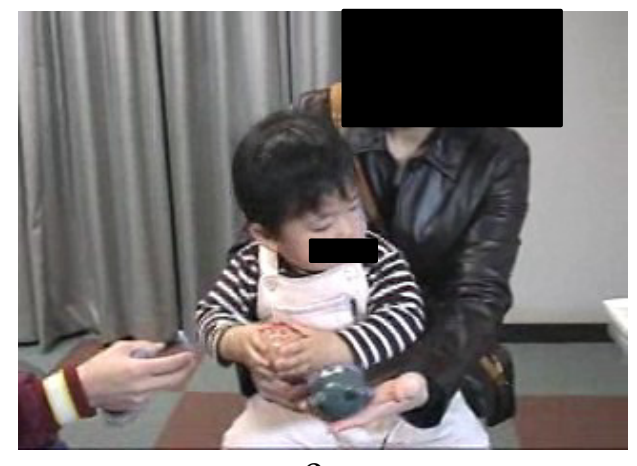

c

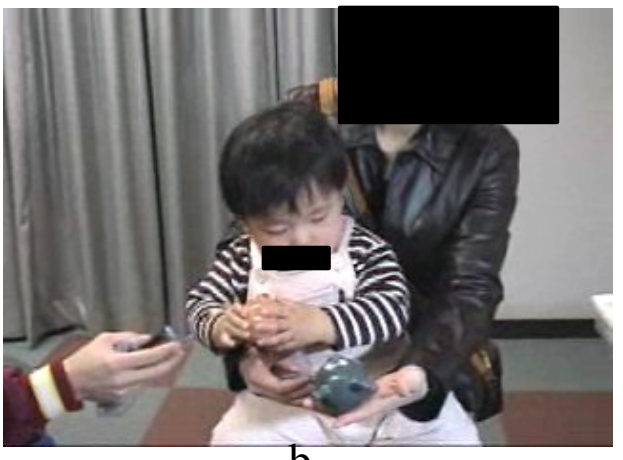

b

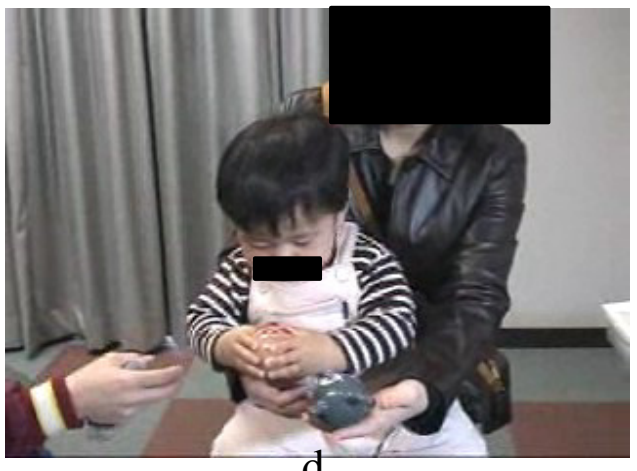

d

Figure 1: Photograph of head thrust movement of case1.
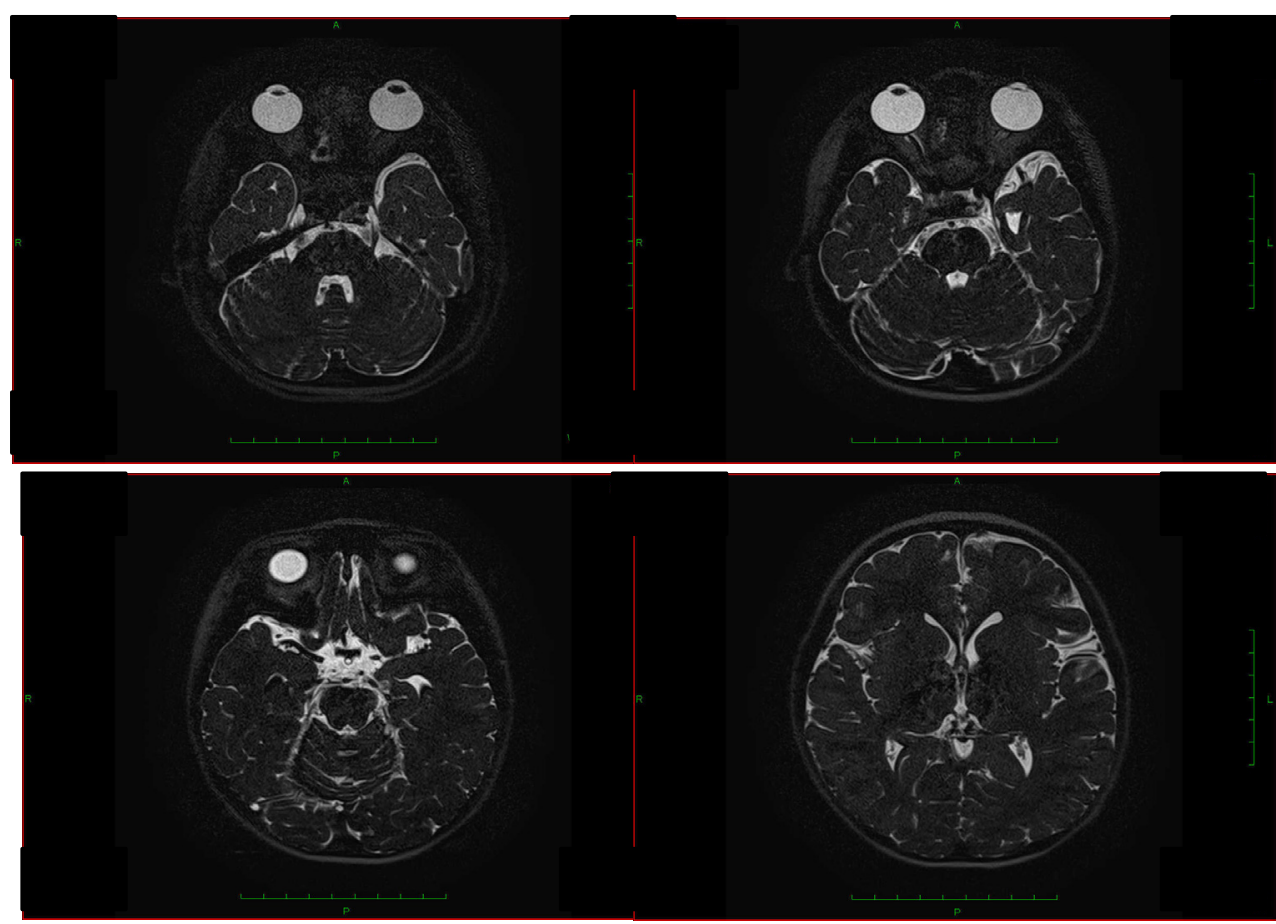

Figure 2: Brain MRI of case 1. T2 axial image shows no hypoplasia of the cerebeller vermis. 


\section{JOJ Ophthalmology}

\section{OD}

OS

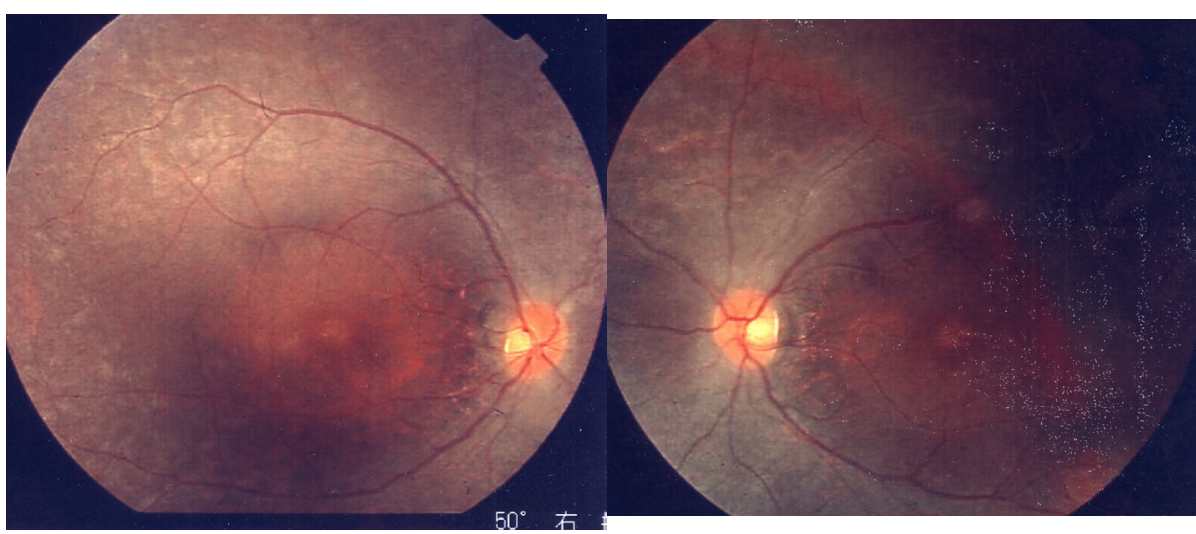

VA $(20 / 200)$

$\mathrm{VA}(20 / 200)$

Figure 3: Fundus photography of case 2. It shows pigmentary retinopathy.

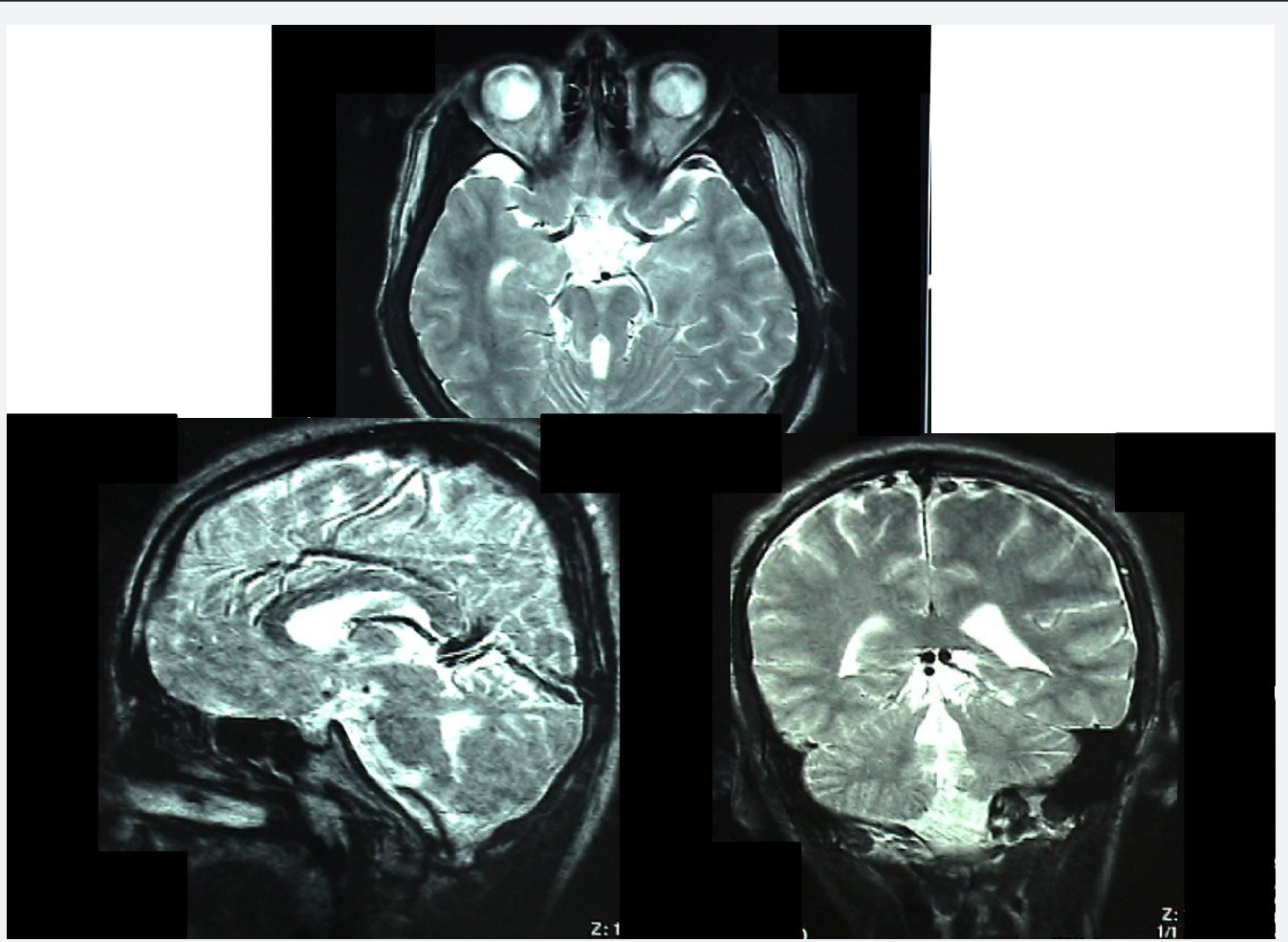

Figure 4: Brain MRI of case 2. Precontrast T1 axial image shows hypoplasia of the cerebeller vermis (molar-tooth sign, white arrow).

\section{Case 6}

A one-year-old girl was noted to have an abnormal head movement. Her past medical and family history were unremarkable. She demonstrated head thrust movement whenever she tried to look at something. Biomicroscopic and fundus examination findings were normal. Brain MRI showed hypoplasia of the cerebeller vermis (Figure 5). She showed no developmental delay nor walking disability up until 6 years of age.

\section{Case 7}

A five-year-old boy was noted to have an abnormal head movement. His past medical history: ependymoma (Figure 6). He demonstrated head thrust movement whenever he tried to 


\section{JOJ Ophthalmology}

look at something. He had a slow saccade. Biomicroscopic and fundus examination findings were normal.

\section{Discussion}

We have observed that cases 1 through 7 all demonstrated head thrust movement which means a disability in saccadic initiation. This "head thrust" movement is the typical clinical characteristic of congenital ocular motor apraxia (COMA).
Joubert syndrome is a syndrome which includes congenital ocular motor apraxia (COMA), pigmentary retinopathy, a mental development delay, respiratory disturbance, and difficulty in walking [3,4]. Maria et al. [5] reported that hypolasia of the cerebeller vermis (Molar-tooth sign) was a characteristic feature of this syndrome [5]. Nowadays, the presence of hypoplasia of the cerebeller vermisis using brain MRI is the key feature in the diagnosis of Joubert syndrome [6].
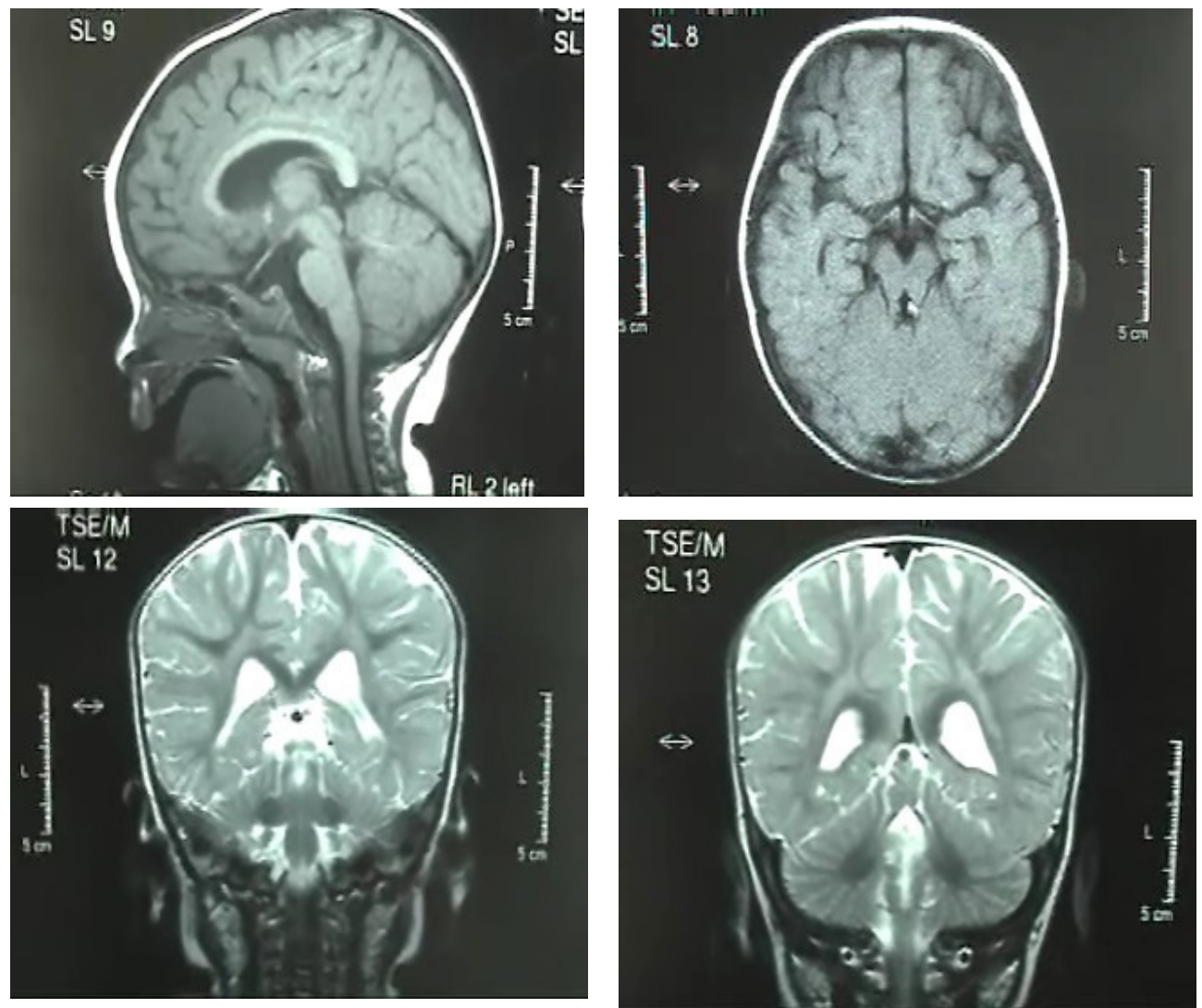

Figure 5: Brain MRI of case 6. Precontrast T1 axial image shows hypoplasia of the cerebeller vermis (molar-tooth sign, white arrow).

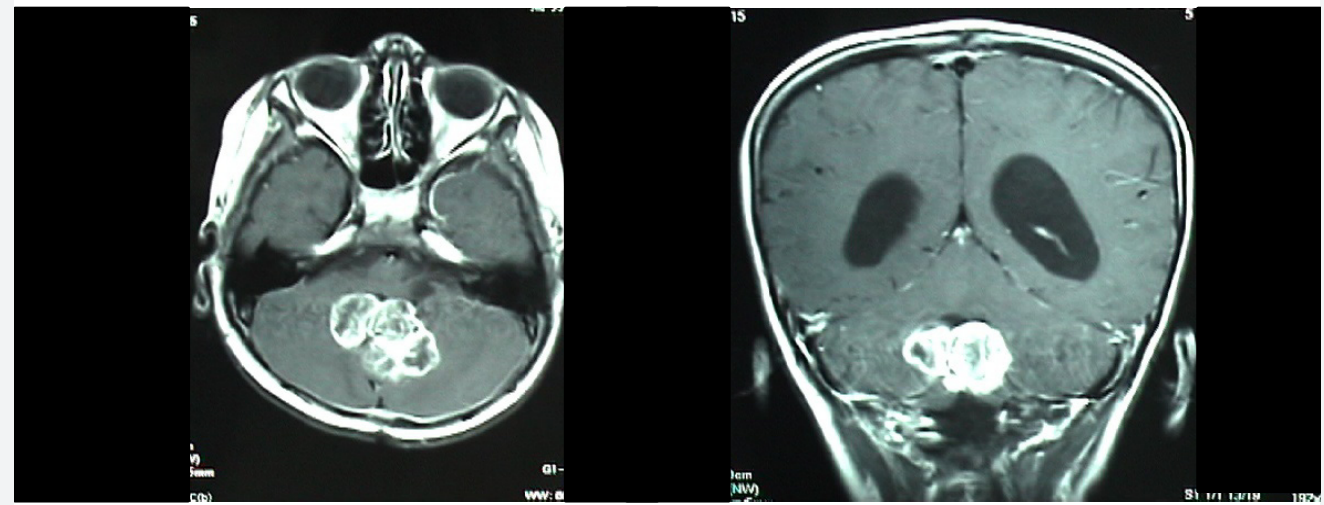

Figure 6: Brain MRI of case 7. Precontrast T1 axial image shows hypoplasia of the cerebeller vermis (molar-tooth sign, white arrow). 
We diagnosed case1 to have classic COMA because of the absence of hypolasia of the cerebeller vermis and other neurological abnormalities. We diagnosed cases 2 through 5 to have Joubert syndrome due to the presence of hypolasia of the cerebeller vermis. We thought that case 6 is between the classic COMA and Joubert syndrome because the clinical presentation is typical for COMA and brain MRI showed very mild cerebeller change but not typical hypoplasia of the cerebeller vermis (Table 1).

It is speculated that the cause of the COMA with head thrust is due to a dysfunction at a location somewhere between the frontal eye field and the paramedian pontine reticular formation (PPRF) [7]. However, the exact pathogenesis of this disorder remains unknown. None of our cases with head thrust had an abnormarity in the frontal eye field, but 4 of 5 cases had hypoplasia at the cerebellar vermis. The autopsy findings of the patients with Joubert syndrome demonstrated hypoplasia of the cerebeller vermis but no abnormalities in the cerebrum including the frontal eye field $[6,8]$. It is well known that patients with COMA improve with age: head thrust movements become less prominent. We therefore speculated that the cause of the COMA, which is characterized by head thrust movement, could be a dysfunction or a developmental delay of the function of the cerebeller vermis.

The weak point of our hypothesis is that in a monkey model in which the cerebellar vermis was destroyed, only hypometric saccade was observed, while no impairment in the initiation of saccade was seen [9]. However, the EOG recorded from patients with Joubert syndrome has been reported to show an impairment of the initiation of saccade, but not of saccadic hypometra [10]. As a result, the cerebeller vermis of humans and monkeys may therefore demonstrate different functions. In addition, case 7 with head thrust as well as a slow saccade demonstrated compression at the cerebeller vermis by the ependymoma.

It is also noted that hypometric saccade has also been reported to induce eye-head movement [2]. Actually acquired ocular motor apraxia patients, who demonstrate damage in the bilateral front-parietal lesions, make eye-head movements to achieve gaze shift more easily [11]. However, it is different from "head thrust" movement in that the velocity is slower and head does not pass the visual object.

It remains a mystery as to why Joubert syndrome demonstrated both a mental and developmental delay while only demonstrating hypolpasia of the cerebeller vermis [12]. However, a recent report on the cerebeller function showed the cerebellum to play an important role in both mental and general development [13]. Therefore, the mental and general developmental delay of Joubert syndrome is has recently been considered to be caused by hypoplasia of the cerebeller vermis [11].

Based on the findings of our cases and a review of both the clinical and experimental evidence described above, we speculated that congenital ocular motor apraxia, as characterized by head thrust, may therefore be caused by a dysfunction of the cerebeller vermis. We hope that further experiments regarding the role of the cerebellum on eye movement will enable us to confirm the validity of our hypothesis.

\section{References}

1. Hodgkins PR, Harris CM, Shawkat FS, Thompson DA, Chong K, et al. (2004) Joubert syndrome: long-term follow-up. Dev Med Child Neurol 46(10): 694-649.

2. Leigh RJ, Zee DS (2006) Eye-Head Movements. In: Leigh RJ \& Zee DS (Eds.), The Neurology of Eye movements. ( $4^{\text {th }}$ edn), Oxford University Press, USA, pp. 332.

3. Joubert M, Eisenring JJ, Robb JP, Andermann F (1969) Familial agenesis of the cerebeller vermis: A syndrome of episodic hyperpnea, abnormal eye movements, ataxia, and retardation. Neurology 19(9): 813-825.

4. Boltshauser E, Isler W (1977) Joubert syndrome: episodic hyperpnea, abnormal eye movements, retardation and ataxia associated with dysplasia of the cerebeller vermis. Neuropadiatrie 8(1): 57-66.

5. Maria BL, Quisling RG, Rosainz LC, Yachnis AT, Gitten J, et al. (1999) Molar tooth sign in Joubert syndrome: clinical, radiologic, and pathologic significance. J Child Neurol 14(6): 368-376.

6. Maria BL, Boltshauser E, Palmer SC, Tran TX (1999) Clinical features and revised diagnostic criteria in Joubert syndrome. J Child Neurol 14(9): 583-590.

7. Leigh RJ, Zee DS (2006) Congenital Ocular Motor Apraxia. In: Leigh RJ \& Zee DS (Eds.), The Neurology of Eye movements. (4 $4^{\text {th }}$ edn), Oxford University Press, USA, pp. 666-669

8. Yachnis AT, Rorke LB (1999) Neuropathology of Joubert syndrome. J Child Neurol 14(10): 655-659.

9. Satoh M, Noda H (1992) Saccadic dysmetria induced by transient functional decortications of the cerebeller vermis. Exp Brain Res 88(2): 455-458.

10. Harris CM, Hodgkins PR, Kriss A, Chong WK, Thompson DA, et al. (1998) Familial congenital saccade initiation failure and isolated cerebellar vermis hypoplasia. Dev Med Child Neurol 40(11): 775-779.

11. Leigh RJ, Zee DS (2006) Acquired Ocular Motor Apraxia. In: Leigh RJ \& Zee DS (Eds.), The Neurology of Eye movements. ( $4^{\text {th }}$ edn), Oxford University Press, USA, pp. 663-666.

12. Kumandas S, Akcakus M, Coskun A, Gumus H (2004) Joubert syndrome: review and report of seven new cases. Eur J Neurol 11(8): 505-510.

13. Ito M (1990) A new physiological concept on cerebellum. Rev Neurol (Paris) 146(10): 564-569. 

CC (1) This work is licensed under Creative BY DOI: $10.19080 /$ JOJO.2017.05.555675
Your next submission with Juniper Publishers will reach you the below assets

- Quality Editorial service

- Swift Peer Review

- Reprints availability

- E-prints Service

- Manuscript Podcast for convenient understanding

- Global attainment for your research

- Manuscript accessibility in different formats

( Pdf, E-pub, Full Text, Audio)

- Unceasing customer service

Track the below URL for one-step submission https://juniperpublishers.com/online-submission.php 